\title{
Valor de preservação do parque Nacional de Ubajara: uma aplicação do método de valoração contingente
}

O Parque Nacional de Ubajara, localizado na região da Serra de Ibiapaba, no estado do Ceará, vem sofrendo com ameaças à qualidade ambiental causadas po fatores naturais e antrópicos. No intuito de apoiar a gestão ambiental da unidade de conservação federal, este estudo utilizou o método de valoração contingente para estimar o valor de preservação do Parque. Para isto, 414 visitantes foram entrevistados, entre os meses de julho e setembro de 2016, por meio de questionário estruturado, para coletar dados sobre seu estado civil, nível de escolaridade, vinculação a organizações ambientais, cidade de origem, número de visitas ao parque tipo de viagem e valor do lance. Utilizando o modelo probit para ajustar as respostas dicotômicas aos lances oferecidos, a disposição a pagar média (DAP) dos visitantes amostrados foi estimada em R\$15,27 (ou US\$ 4.03 no ano base 2019); o que corresponde ao benefício líquido de R\$ 1.570.000,00 (ou US\$ 414,240 ) anuais oriundo da visitação, considerando as melhorias na qualidade ambiental propostas no cenário hipotético. Esses resultados demonstram que o valor da preservação dos bens e serviços ambientais ofertados pelo Parque Nacional de Ubajara é significativo, inclusive sendo superiores à de outros espaços especialmente protegidos no Brasil, justificando também termos monetários a preservação e conservação da reserva ecológica.

Palavras-chave: Parque Nacional; Valoração Contingente; Preservação; Brasil.

\section{The preservation value of Ubajara National park: an application of the contingent valuation method}

\begin{abstract}
The Ubajara National Park, located in the Serra de Ibiapaba region in the state of Ceará, has suffered from threats to environmental quality caused by natural and anthropic factors. In order to support the environmental management of the federal conservation unit, this study utilized the contingent valuation method to estimate the preservation value of the Park. To do that, 414 visitors were interviewed, between the months of July and September of 2016, through a structured questionnaire aiming to gather data about their marital status, level of schooling, linkage to environmental organizations, city of origin, number of visits to the park, type of trip and bid value. Using the probit model to adjust the dichotomous responses to the lance offered, the mean willingness to pay (WTP) of the sampled visitors was estimated in R\$15,27 (US\$ 4.03 in the 2019 base year), which corresponds to the net benefit of R\$1.570.000,00 (or US\$ 414,240) per year from the visitation, considering the improvements in environmental quality proposed in the hypothetical scenario. The results showed that the preservation value of the environmental goods and services offered by the Ubajara National Park is significant, being even higher than the value of other protected areas in Brazil, justifying also in monetary terms the preservation e conservation of the ecological reserve.
\end{abstract}

Keywords: National Park; Contingent Valuation; Preservation; Brazil.

Topic: Desenvolvimento, Sustentabilidade e Meio Ambiente

Reviewed anonymously in the process of blind peer
Received: 12/04/2019

Approved: 27/05/2019
Tiago Bessa Aragão (iD

Universidade Estadual do Ceará, Brasil

http://lattes.cnpq.br/7666800198774986

http://orcid.org/0000-0002-3115-8295

tiagotba@yahoo.com.br

Rogério César Pereira de Araújo (ic

Universidade Estadual do Ceará, Brasil

http://lattes.cnpq.br/2048684813061911

http://orcid.org/0000-0002-5716-3236

rcpa@ufc.br 


\section{INTRODUÇÃO}

No mundo, a designação de áreas especialmente protegidas é utilizada como estratégia para a preservação de comunidades biológicas. No Brasil, as áreas protegidas são denominadas por Unidades de Conservação da Natureza (UC's) cujo objetivo geral é a proteção da biodiversidade por meio de regimes especiais de administração e manejo dos recursos naturais.

Dentre as várias categorias de UC's, até o ano de 2016, os Parques Nacionais (PARNA) somavam 72 unidades, correspondendo a $262.147,07 \mathrm{~km}^{2}$. O parque nacional tem como objetivo básico a preservação de ecossistemas naturais de grande relevância ecológica e beleza cênica, restringindo-se os usos pelo homem apenas à realização de pesquisas científicas, educação ambiental e o turismo ecológico (BRASIL, 2000).

Apesar de desempenharem serviços ecossistêmicos e recreativos relevantes à proteção do patrimônio natural e ao bem-estar da população, os parques nacionais estão sujeitos a ameaças constantes à sua biodiversidade, tais como incêndios florestais, caça predatória, desmatamentos, represamento e aterramento de recursos hídricos, inclusive de nascentes.

O Instituto Chico Mendes de Conservação da Biodiversidade (ICMBio), órgão ambiental brasileiro responsável pela gestão dos parques nacionais, tem encontrado dificuldades para realizar suas ações de monitoramento e fiscalização sem intercorrências. Essas dificuldades estão associadas à insuficiência de recursos financeiros advindos do Governo Federal ou à baixa arrecadação de taxas de visitação na própria UC. Tal situação compromete a execução de ações protetivas/combativas e, evidentemente, aquelas que objetivem a melhoria dos benefícios ecossistêmicos e recreativos desses sítios.

Nesse contexto, insere-se o Parque Nacional de Ubajara (PNU), localizado na região da Serra de Ibiapaba, no estado do Ceará. Este parque é o único no país onde é possível observar a transição entre vegetações típicas de ambientes seco e úmido, diferenciando-se marcantemente do bioma que integra Caatinga - por possuir características de fauna e flora diferentes daquelas típicas do semiárido que o circunda. O PNU possui habitats de espécies da fauna endêmicas e ameaçadas de extinção, além do maior acervo espeleológico do estado do Ceará, com potencial paleontológico significativo. Esse parque é destino para visitantes que buscam experiências de recreação, lazer e turismo (BRASIL, 2007).

Apesar da sua importância para a preservação da biodiversidade, historicamente, o PNU vem sofrendo com ameaças à qualidade ambiental, causadas por fatores naturais e antrópicas. Além disso, cerca de $90 \%$ de sua área, que sofreu ampliação em 2002, não foi objeto de regularização fundiária. Dos projetos e programas previstos no Plano de Manejo em 2002, somente um terço deles foram realizados até o ano de 2010. Somado a isto, o repasse financeiro do governo federal para os parques nacionais têm declinado a cada ano. ${ }^{1}$

Esse contexto aponta para a necessidade de criar as condições financeiras, humanas e materiais suficientes para a regularização fundiária da área do parque e a execução plena do seu plano de manejo. Diante da ineficiência da ação do governo federal, no longo prazo, a tendência atual de falta de recursos

${ }^{1}$ Informação fornecida pela gerência do PNU, em agosto de 2016. 
pode significar a perda de parte significativa do patrimônio natural do PNU.

A mudança da atitude do tomador de decisão governamental com relação ao PNU depende do seu conhecimento sobre o valor econômico do Parque para a sociedade e quanto representa a perda econômica do seu patrimônio natural para esta. Esse valor representa o acréscimo ou decréscimo nos níveis de bemestar da população relevante por mudanças que ocorrem na qualidade e/ou quantidade dos serviços ambientais da unidade.

Por ser expresso em termos de valor monetário, podem-se comparar os valores dos bens e serviços transacionados no mercado, tornando os benefícios e custos dos serviços ambientais comparáveis aos outros bens e serviços de mercado. Desta forma, os dilemas de escolha inerentes na tomada de decisão de políticas públicas podem levar em consideração também os impactos positivos e negativos de ações humanas sobre o meio ambiente. Nesse sentido, este estudo propõe-se a mensurar a disposição a pagar (DAP) média do visitante para a preservação do PNU e identificar os fatores socioeconômicos e demográficos dos visitantes que afetam significativamente a atitude de preservação do PNU.

\section{REVISÃO TEÓRICA}

\section{Valoração Contingente}

O método de Valoração Contingente (MVC) é uma técnica de preferência declarada que utiliza questionários para aferir o comportamento intencionado do indivíduo diante de um contexto ou mercado hipotético. O mercado hipotético envolve a descrição do contexto institucional no qual uma política, programa ou projeto propõe uma mudança na quantidade ou qualidade de bem ou serviço ambiental. Diante desse contexto, solicita-se ao respondente que manifeste a sua preferência pelo bem por meio da disposição a pagar (ou disposição a receber) (MITCHELL et al., 1989). Assume-se que o respondente faz sua escolha como se estivesse num mercado real (OECD, 2018). O MVC tem como vantagens sua flexibilidade por ser de natureza hipotética e ser aplicável, em princípio, a quase todos os bens de não mercado, e poder estimar todos os tipos de benefícios dos bens de não mercado (valor de uso e não uso).

\section{Aplicações do método}

No contexto internacional, além de outros trabalhos também relevantes, destacam-se González (2009), Abedini et al. (2016) e Baral et al. (2017) que utilizaram o método de valoração contingente para estimar a disposição a pagar média ou os valores econômicos de parques ou áreas protegidas. Valores de referência ajustados para o ano-base 2017.

González (2009) utilizou os métodos de custo de viagem (MCV) e de valoração contingente (MVC) para estimar o benefício econômico do uso do Parque Nacional Cerro Corá, no Paraguai. O valor recreativo do parque estimado pelo MCV foi US\$ 71,550.00 por ano enquanto o valor anual de não uso estimado pelo MVC foi US\$ 67,125.00, que somado totalizaram US\$ 138,675.00 (R\$ 443.538,12).

Abedini et al. (2016) estimou o valor recreativo e a disposição a pagar dos frequentadores do Parque 
da Floresta Lavizan no Irã. Os autores estimaram a disposição a pagar média dos visitantes para a visitação e preservação da reserva em IRR\$ 3,696 (ou R\$ 0,36). O valor recreativo anual do parque foi estimado em IRR\$ 6.996.861,925 (ou $\mathrm{R} \$ 685.692,47$ ).

Baral et al. (2017) aplicou o método de valoração contingente para estimar a disposição a pagar dos visitantes internacionais pelo ingresso no Parque Nacional de Sagarmatha, no Nepal. Esse parque é considerado um patrimônio mundial pelo fato de abrigar o Monte Evereste. A disposição a pagar média foi estimada em US\$ 90,93 por viagem sendo influenciada significativamente pela renda, idade, gênero, tempo de permanência no parque, informação sobre parques substitutos e conhecimento sobre sua designação como patrimônio natural por parte do visitante.

No Brasil, os métodos de valoração econômica ambiental também vêm sendo utilizados para estimar os valores de uso e não-uso das unidades de conservação. Braga et al. (2013) aplicou o método de valoração contingente para estimar a disposição a pagar para a preservação/conservação do PARNA da Lagoa do Peixe/RS. Os autores estimaram uma DAP média dos visitantes de $\mathrm{R} \$ 15,87$ por visitante, que agregado para a população relevante gerou um valor econômico total anual de $\mathrm{R} \$ 109.450,46$. Contatou-se também que a disposição a pagar média foi afetada positiva e significativamente pelo nível de renda e grau de escolaridade dos visitantes.

Carvalho (2012) estimou a valor econômico da conservação do PARNA da Chapada Diamantina/BA por meio do método de valoração contingente. A autora estimou em $\mathrm{R} \$ 5.229 .451,50$, o benefício líquido da conservação do parque. Resende et al. (2014) estimou o valor dos benefícios oferecidos pelo PARNA da Serra do Cipó, localizado no estado de Minas Gerais. Com base numa amostra de 514 visitantes, o valor anual do parque foi estimado em aproximadamente $\mathrm{R} \$ 885.218,87$.

O método de valoração contingente tem sido amplamente aplicado para estimar o valor de preservação/conservação dos parques, no âmbito nacional e internacional. Nesse estudo, recorre-se aos trabalhos apresentados nessa revisão de literatura para apoiar as decisões teóricas e metodológicas relativas à aplicação desse método no contexto do Parque Nacional de Ubajara.

\section{METODOLOGIA}

\section{Caracterização da área de estudo}

A área de estudo compreende o Parque Nacional de Ubajara, localizado no noroeste do estado do Ceará, em Ubajara-CE, sendo delimitado pelas coordenadas geográficas 352'05"S / 4057'55,6" O e 340'49"S / 4052'17,5" O. O Parque Nacional de Ubajara fica a $340 \mathrm{~km}$ da cidade de Fortaleza. Criado em 30 de abril de 1959 por meio do Decreto Federal n 45.954, com uma área inicial de 4.000 ha, em 1973, a área do parque foi alterada para 563 ha (BRASIL, 1973). No ano de 2002, sua área foi modificada novamente, passando a contar com os atuais 6.288 ha (BRASIL, 2002).

Esta unidade de conservação (UC) inclui-se nas regiões de planejamento da Serra da Ibiapaba e do Sertão de Sobral do Governo do Ceará (CEARÁ, 2016), estendendo-se sobre partes dos municípios de 
Ubajara, Tianguá e Frecheirinha (Figura 1). Por ser de nível administrativo federal, a gestão da UC é de competência do ICMBio.

O PNU possui ecossistemas diversos, tais como Caatinga, Floresta Subperenifólia Tropical e transição Floresta/Caatinga. Esta unidade é considerada o terceiro menor parque nacional brasileiro e o menor do bioma Caatinga, possuindo ainda inúmeros atrativos naturais como cavernas, cachoeiras, rios, diversas espécies da fauna e flora e uma magnífica beleza cênica. No PNU já foram identificadas 127 espécies de aves, 33 espécies de répteis, 19 espécies de anfíbios e 41 espécies de mamíferos, inclusive possui espécies ameaçadas de extinção (IBAMA, 2002; BRASIL, 2007).

O PNU dispõe de infraestrutura e equipamentos para a realização de atividades de turismo ecológico, educação e interpretação ambiental, e, realização de pesquisas científicas, tais como o centro de visitantes e museu, casa da árvore, trilhas, mirantes e teleférico para acesso à gruta de Ubajara, sendo este a principal atração do sítio.

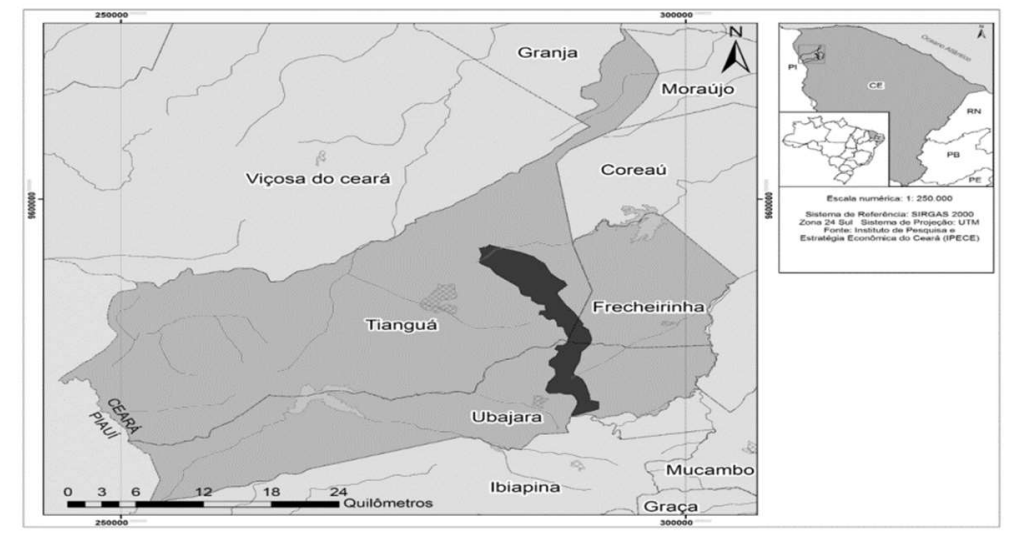

Figura 1: Mapa de localização do Parque Nacional de Ubajara.

\section{Método de Valoração Contingente}

\section{Mercado hipotético}

O mercado hipotético apresenta o contexto corrente de ameaças e riscos sobre a qualidade ambiental do PNU. O contexto hipotético foi estruturado de tal forma a oferecer informações relevantes ao respondente sobre a importância do PNU para a preservação da biodiversidade regional e provisão de serviços culturais (recreação, educação ambiental e pesquisa científica), fatores determinantes das ameaças e riscos ambientais, necessidade de aporte financeiro para a gestão ambiental, proposta de um mercado hipotético embasada na cobrança de taxa de ingresso, formação do Fundo de Preservação do PNU e forma de controle de gastos. Esse mercado hipotético garantiria a execução das ações previstas no Plano de Manejo do PNU e que asseguraria a preservação e conservação da biodiversidade e da qualidade das atividades culturais (recreação, turismo, educação ambiental, pesquisa científica etc.) oferecidas pela unidade de conservação.

\section{Modelo empírico}

Nesse estudo, a valoração contingente tem como objetivo estimar a função de demanda pela 
preservação dos serviços ambientais $(\mathrm{Q})$ providos pelo Parque Nacional de Ubajara aos seus visitantes. Para isto, um modelo utilidade é definido a partir do qual se estima a disposição a pagar (DAP) do visitante por melhoria na qualidade ambiental e das experiências recreativas do PNU decorrente das ações de preservação.

Propõe-se como veículo de pagamento do visitante uma taxa adicional de ingresso individual por dia de visita, além do valor da taxa de ingresso individual corrente já cobrada pelo condutor de visitação. Para captar a DAP, optou-se pelo referendo como forma de elicitação que também é conhecida por a técnica de escolha dicotômica.

A escolha dicotômica, segundo Motta (1997), é preferível, pois tanto permite menor ocorrência de lances estratégicos dos entrevistados ('lances mais próximos de zero') quanto aproxima-se da verdadeira experiência de mercado no qual ações de consumo são determinadas frente a preços previamente definidos.

A estrutura de valoração é composta de três questões: (1) questão de participação; (2) questão de valoração propriamente dita; e (3) questões de verificação (follow up). Depois de apresentado o contexto hipotético ao respondente, indagou-se a ele se concordava ou não com a cobrança da taxa para a formação de um Fundo de Preservação do PNU, a qual se constitui na questão de participação (Questão 1). Em seguida, o respondente foi solicitado a apontar a principal motivação que o fez escolher Sim ou Não para o mercado hipotético. Esta questão permitiu ao analista identificar a resposta de protesto em caso de Não ou o principal motivo de sua participação em caso de Sim.

A questão de valoração (Questão 2) é feita ao respondente que aceitou a cobrança da taxa adicional exposta no mercado hipotético. Nesta questão, um lance específico é apresentado ao respondente e pergunta-se a ele se estaria disposto a pagar aquele valor como taxa adicional por dia de visita. A cada respondente foi apresentado apenas um único valor entre os seis valores possíveis, a saber: $R \$ 5, R \$ 10, R \$ 15$, $\mathrm{R} \$ 20, \mathrm{R} \$ 25$ e $\mathrm{R} \$ 30$. Esses lances foram aleatória e sistematicamente distribuídos proporcionalmente na amostra.

O método de referendo pressupõe que o usuário do recurso é solicitado a votar a favor (dizendo sim) ou contra (dizendo não), diante do contexto hipotético que propõe uma melhoria na qualidade ambiental do PNU, de $q_{0}$ para $q_{1}\left(q_{1}>q_{0}\right)$, mediante o pagamento de uma taxa adicional de ingresso $(t)$. Considerando todos os outros fatores constantes, esse aumento em $q$ deixaria o usuário pelo menos numa situação de indiferença entre possuir maior renda e usufruir menor qualidade ambiental e reduzir a renda ao pagar a taxa e usufruir maior nível de qualidade ambiental.

Segundo Hanemann et al. (1996), a probabilidade da resposta sim é expressa por uma distribuição de probabilidade cumulativa de $\eta\left(F_{\eta}\right)$ que dependem da taxa $(t)$, renda $(y)$, características socioeconômicas $(s)$ e do conjunto de parâmetros associados ao vetor de covariância $(y ; s)$, como expresso na equação 1.

$$
\operatorname{Pr}(\operatorname{Sim})=\operatorname{Pr}(l=1)=F_{\eta}(\Delta V)
$$

A Variação Compensatória $(C)$ expressa o montante a ser pago em dinheiro pelo indivíduo a fim de compensar pelo aumento na qualidade ambiental sendo provida de tal forma a mantê-la no menor nível de utilidade. Portanto, a variação compensatória representa a disposição a pagar máxima $(D A P)$ do indivíduo 
pela melhoria ambiental proposta. Em termos de utilidade direta, a $D A P$ pode ser observada na expressão 2.

$$
V\left(y-D A P, q_{1} ; s\right)=V\left(y, q_{0} ; s\right)
$$

O modelo econômico e estatístico da variação compensatória considera que o indivíduo possui máxima disposição a pagar positiva quando $\operatorname{Pr}(\operatorname{Sim})=\operatorname{Pr}(l=1)=F_{\eta}(\Delta V)$, também expresso na equação 3.

$$
\operatorname{Pr}(\operatorname{Sim})=\operatorname{Pr}(l=1)=\operatorname{Pr}\left(D A P\left(q_{0}, q_{1}, y ; s, \eta\right) \geq t\right)
$$

Para estimar os parâmetros da função de utilidade direta $(\Delta V)$, que é uma variável dependente qualitativa, assume-se $\eta \sim N(0,1)$, o que torna $F_{\eta}(\Delta V)$ uma distribuição cumulativa normal padronizada. Esta função é denominada de modelo probit e pode ser estimada por meio da maximização da função de verossimilhança, como mostrada na Equação 6.

$$
\log L=\sum_{i}^{n}\left[y_{i} \log F_{\eta}(\Delta V)+\left(1+y_{i}\right) \log \left(1-F_{\eta}(\Delta V)\right]\right.
$$

Para esta análise, assumiu-se que $\Delta V$ é expressa por uma função de nível, ou seja, linearmente associadas às variáveis explicativas, o que garante utilidade marginal da renda constante (MINGOTI, 2005). De acordo com López-Feldman (2012), depois de obtidas as estimativas dos parâmetros dessa função, o valor esperado da DAP (ou DAP Média, $D A P^{*}$ ) é estimada pela seguinte equação 5.

$$
D A P^{*}=E\left(D A P_{i} \mid s_{i}, \hat{\alpha}, \hat{\beta}\right)=\left(-\frac{\hat{\alpha}}{\hat{\beta}}\right) \cdot s_{i}
$$

onde: $\hat{\alpha}$ é o vetor estimado dos coeficientes associados a cada uma das variáveis explicativas; $\hat{\beta}$ é a estimativa do coeficiente do lance; e $s_{i}$ é o vetor das variáveis explicativas com os valores de interesse.

A agregação da disposição a pagar para a população relevante, ou seja, os visitantes do Parque Nacional de Ubajara, é feita multiplicando a DAP média estimada pela média do número de visitantes do Parque. Como mostrado na Equação 5, o vetor de variável explicativa $s_{i}$ reúne o conjunto de características socioeconômicas do indivíduo que afeta a $D A P^{*}$ (GONZÁLEZ, 2009). O Quadro 1 apresenta a descrição das variáveis incluídas no modelo probit para valorar a preservação do PNU.

A variável dependente é a resposta do respondente à questão de valoração, a qual assume escore de valor 1 para a resposta sim e 0 para a resposta não, quanto a possuir ou não disposição a pagar pela preservação do PNU. As variáveis explicativas são o valor do lance apresentado ao respondente e suas características socioeconômicas: sexo, idade, tamanho da família, nível de escolaridade, renda mensal familiar e filiação em organização ambiental. Com exceção da idade do respondente, as demais variáveis explicativas foram incorporadas nos modelos como variáveis dicotômicas (ou dummy).

A análise econométrica consistiu em estimar dois modelos probit, a saber: MPI - Modelo Probit Irrestrito, no qual se incluiu todas as variáveis dependentes; e MPR - Modelo Probit Restrito, no qual manteve-se apenas as variáveis explicativas que se mostraram significativas no MPI. O nível de significância utilizado para reter a variável explicativa foi de $10 \%$, pelo fato da maioria das variáveis serem dicotômicas.

Quadro 1: Descrição das variáveis explicativas adotadas no método de custo de viagem.

\begin{tabular}{|l|l|l|l|}
\hline Variável & Definição & Sigla \\
\hline Disposição a pagar do & Variável latente que captura a existência de disposição a pagar do respondente: Sim & $D A P$ \\
\hline
\end{tabular}




\begin{tabular}{|c|c|c|}
\hline indivíduo & $=1 ; \mathrm{Não}=0$ & \\
\hline Lance & $\begin{array}{l}\text { Valores dos lances oferecidos ao respondente: } R \$ 5, R \$ 10, R \$ 15, R \$ 20, R \$ 25 \text { ou } \\
R \$ 30 \text {. }\end{array}$ & LANCE \\
\hline Sexo & Gênero do respondente: 1 , se masculino; 0 , se feminino. & SEXO \\
\hline Idade & Idade do respondente, variando no intervalo entre 18 e 68 anos & IDADE \\
\hline Estado Civil & $\begin{array}{l}\text { Estado civil do respondente: } 1 \text {, se casado ou união estável; e } 0 \text {, se divorciado, viúvo } \\
\text { ou solteiro. }\end{array}$ & ESTCIVIL \\
\hline Tamanho da Família & Número de pessoas que compõem a família do respondente & TFAMILIA \\
\hline \multirow[t]{3}{*}{ Nível de Escolaridade } & 1, se analfabeto ou ensino fundamental (completo ou incompleto); 0, caso contrário. & NESCOLAR1 \\
\hline & 1, se possui ensino médio (completo ou incompleto); 0 , caso contrário. & NESCOLAR2 \\
\hline & $\begin{array}{l}\text { 1, se possui ensino superior ou pós-graduação (completo ou incompleto); 0, caso } \\
\text { contrário. }\end{array}$ & NESCOLAR3 \\
\hline \multirow{4}{*}{$\begin{array}{l}\text { Renda Mensal } \\
\text { Familiar }\end{array}$} & 1 , se possui renda de até $\mathrm{R} \$ 3.520 ; 0$, caso contrário. & RMF1 \\
\hline & 1, se possui renda entre $\mathrm{R} \$ 3.521$ e $\mathrm{R} \$ 7.040 ; 0$, caso contrário. & RMF2 \\
\hline & 1, se possui renda entre $\mathrm{R} \$ 7.041$ e $\mathrm{R} \$ 10.560 ; 0$, caso contrário. & RMF3 \\
\hline & 1 , se possui renda maior que $\mathrm{R} \$ 10.6561 ; 0$, caso contrário. & RMF4 \\
\hline $\begin{array}{l}\text { Membro de Organização } \\
\text { Ambiental }\end{array}$ & $\begin{array}{l}\text { Relativa à filiação do respondente a entidades de cunho ambiental: } 1 \text {, se é filiado; } 0 \text {, } \\
\text { se não é filiado. }\end{array}$ & MORGAMB \\
\hline Origem-Fortaleza & $\begin{array}{l}\text { Visitante teve origem da sua viagem na cidade de Fortaleza: } 1 \text {, se partiu de Fortaleza; } \\
0 \text {, caso contrário. }\end{array}$ & OFORTAL \\
\hline Número de Visitas & Número de visitas feitas pelo respondente ao PNU. & NVISITAS \\
\hline Múltiplos Destinos & $\begin{array}{l}\text { Tipo de viagem ao PNU: } 1 \text {, se a viagem é de múltiplos destino; } 0 \text {, se é de destino } \\
\text { único. }\end{array}$ & MULTDEST \\
\hline Tamanho do Grupo & Tamanho do grupo do qual respondente faz parte, inclusive contando com ele. & TGRUPO \\
\hline
\end{tabular}

\section{Amostra}

A população da pesquisa é formada pelos visitantes domésticos do PNU. O tamanho da amostra de visitantes foi calculado com base no número de visitantes ao PNU, no período de 2010 a 2015, registrado pela própria unidade. Em termos médios, o total anual de visitantes do PNU foi de 100.684 pessoas. O maior fluxo de visitantes ocorre no período de Alta estação (dezembro, janeiro e julho), correspondendo ao percentual de $36,7 \%$ dos visitantes. O período de Baixa estação abrange os outros nove meses, correspondendo a $63,3 \%$ dos visitantes.

Para o cálculo da amostra, assumiu-se nível de confiança de 95\%, margem de erro de $5 \%$ e proporção da variável de interesse na população de 50\%. O tamanho mínimo da amostra foi estimado em 383 visitantes. Efetivamente foram coletadas 417 observações, $9 \%$ a mais do que a amostra representativa prevista, a fim de garantir a reposição de possíveis perdas de questionários por falhas de preenchimento. Essa amostra foi distribuída proporcionalmente entre as estações Alta e Baixa, tendo sido aplicados 180 (43,2\%) questionários na Alta estação e 237 (56,8\%), na Baixa estação.

\section{Questionário}

Para a coleta dos dados foi utilizado um questionário estruturado em oito seções, formado por questões de múltipla-escolha, relação dicotômica (sim/não), questões abertas e respostas hierarquicamente ordenadas. O questionário foi aplicado de forma direta a visitantes selecionados aleatoriamente, depois de realizarem a visita ao PNU. Os questionários foram aplicados durante dois períodos: (i) no período de Alta estação, de 29 a 31 de julho de 2016; e (ii) no período de Baixa estação, nos dias 6 e 7 de agosto e 10 e 11 de setembro de 2016. 


\section{RESULTADOS}

\section{Caracterização do visitante}

A Tabela 1 mostra as frequências absoluta e relativa da idade, sexo e estado civil da amostra de visitantes do PNU.

Tabela 1: Estatística descritiva da idade, sexo e estado civil dos visitantes do PNU.

\begin{tabular}{|l|l|l|}
\hline \multirow{2}{*}{ Especificação } & Frequência & Relativa \\
\cline { 2 - 3 } & Absoluta & \\
\hline Idade & & $47,6 \%$ \\
\hline 18 a 30 anos & 197 & $29,2 \%$ \\
\hline 31 a 40 anos & 121 & $14,0 \%$ \\
\hline 41 a 50 anos & 58 & $5,8 \%$ \\
\hline 51 a 60 anos & 24 & $3,4 \%$ \\
\hline Mais de 60 anos & 14 & $100,0 \%$ \\
\hline Total & 414 & \\
\hline Sexo & & $52,2 \%$ \\
\hline Masculino & 216 & $47,8 \%$ \\
\hline Feminino & 198 & $100,0 \%$ \\
\hline Total & 414 & \\
\hline Estado civil & & $39,1 \%$ \\
\hline Solteiro(a) & 162 & $57,5 \%$ \\
\hline Casado(a)/União Estável & 238 & $2,7 \%$ \\
\hline Divorciado(a) & 11 & $0,7 \%$ \\
\hline Viúvo(a) & 3 & $100,0 \%$ \\
\hline Total & 414 & \\
\hline
\end{tabular}

O perfil médio do visitante pode ser caracterizado por ser do sexo masculino (52,2\%), estar na faixa de idade entre 18 e 30 anos (47,6\%) e ser casado ou possuir união estável (57,5\%). Porém, vale destacar que a diferença dos percentuais entre homens e mulheres é pequeno $(4,3 \%)$ e o percentual de visitantes solteiros é também significativo (39,1\%). A Tabela 2 mostra as frequências absoluta e relativa da escolaridade, renda mensal familiar e filiação à organização ambiental da amostra de visitantes do PNU.

Em relação ao nível de escolaridade, um em cada três entrevistados possuía o ensino médio completo ou incompleto, ou seja, 33,8\% da amostra. Deve-se destacar a considerável participação na amostra de visitantes com ensino fundamental, representando $28,5 \%$ da amostra, e com pós-graduação (28,3\%). Porém, a predominância da amostra foi de visitantes com escolaridade até o ensino médio, correspondendo a 62,3\% dos entrevistados.

Analisando as faixas de renda mensal familiar de forma agregada, a maioria dos visitantes incluía-se no intervalo de renda mensal familiar entre $\mathrm{R} \$ 5.281$ e $\mathrm{R} \$ 10.560$, correspondendo a 46,4\% dos entrevistados. O segundo maior percentual de visitantes incluiu-se na menor faixa de renda familiar, até R\$ 5.280 , representando $34,5 \%$ da amostra. Finalmente, o intervalo de renda mensal familiar superior, indo de $\mathrm{R} \$ 10.561$ a mais de $\mathrm{R} \$ 14.081$, figurou com $19,1 \%$ dos visitantes pesquisados.

Indagado quanto sua participação em associações ou organizações (público ou privada) envolvidas na temática ambiental, a maioria dos entrevistados respondeu não ser membro. Os visitantes amostrados no PNU somaram 414 pessoas, originadas de doze estados brasileiros, além do Distrito Federal (5), sendo eles: Amazonas (4), Bahia (6), Ceará (264), Espírito Santo (1), Maranhão (13), Pará (2), Paraíba (3), 
Pernambuco (6), Piauí (89), Rio de Janeiro (11), Rio Grande do Norte (3) e São Paulo (7). Os visitantes da região Nordeste representaram 93\% da amostra, ficando os estados do Ceará e Piauí com os maiores percentuais, $63,8 \%$ e $21,5 \%$, respectivamente.

Tabela 2: Estatística descritiva da escolaridade, renda familiar e filiação à organização ambiental dos visitantes do PNU.

\begin{tabular}{|l|l|l|}
\hline \multirow{2}{*}{ Especificação } & Frequência & Relativa \\
\cline { 2 - 3 } & Absoluta & \\
\hline Escolaridade & & $0,5 \%$ \\
\hline Nem lê, nem escreve & 2 & $28,5 \%$ \\
\hline Fundamental Comp./Inc. & 118 & $33,8 \%$ \\
\hline Médio Comp./Inc. & 140 & $8,9 \%$ \\
\hline Superior Comp./Inc. & 37 & $28,3 \%$ \\
\hline Pós-graduação Comp./Inc. & 117 & $100,0 \%$ \\
\hline Total & 414 & \\
\hline Renda mensal familiar & & $5,8 \%$ \\
\hline Menos de R\$ 880 & 24 & $8,7 \%$ \\
\hline De R\$ 880 a R\$ 1.760 & 36 & $12,8 \%$ \\
\hline De R\$ 1.761 a R\$ 3.520 & 53 & $7,2 \%$ \\
\hline De R\$ 3.521 a R\$ 5.280 & 30 & $20,5 \%$ \\
\hline De R\$ 5.281 a R\$ 7.040 & 85 & $4,8 \%$ \\
\hline De R\$ 7.041 a R\$ 8.880 & 20 & $21,0 \%$ \\
\hline De R\$ 8.881 a R\$ 10.560 & 87 & $3,6 \%$ \\
\hline De R\$ 10.561 a R\$ 12.230 & 15 & $12,1 \%$ \\
\hline De R\$ 12.231 a R\$ 14.080 & 50 & $3,4 \%$ \\
\hline Mais de R\$14.081 & 14 & $100,0 \%$ \\
\hline Total & 414 & \\
\hline Filiação a Organização Ambiental & & $5,3 \%$ \\
\hline Sim & 22 & $92,3 \%$ \\
\hline Não & 382 & $2,4 \%$ \\
\hline Não informou & 10 & $100,0 \%$ \\
\hline Total & 414 & \\
\hline & & \\
\hline
\end{tabular}

As cidades do Ceará e de estados limítrofes possuíam as maiores demandas por serviços de recreação do PNU, já que essas cidades estão localizadas a menos de 100 km da UC. Do total da amostra de visitantes, cerca de $84 \%$ dos entrevistados eram provenientes da cidade onde residiam. A principal motivação para visitar o PNU mostrou-se variada e distribuída quase equitativamente entre os visitantes, como mostra a Tabela 3. Visitar museus e exposições recebeu apenas 1,9\% das indicações dos visitantes, o que evidencia que esses atrativos culturais são pouco valorizados pelos entrevistados.

Tabela 3: Principal motivação para visitar o PNU.

\begin{tabular}{|l|l|l|}
\hline Especificação & Frequência & Relativa \\
\cline { 2 - 3 } & Absoluta & $1,9 \%$ \\
\hline Visitar museus e exposições & 8 & $5,1 \%$ \\
\hline Visitar cachoeiras e lagos & 21 & $11,4 \%$ \\
\hline Apreciar a fauna/flora & 47 & $13,8 \%$ \\
\hline Conhecer a grupa & 57 & $15,9 \%$ \\
\hline Percorrer trilhas & 66 & $24,9 \%$ \\
\hline Ter contato com a Natureza & 103 & $27,1 \%$ \\
\hline Andar no bondinho & 112 & $100,0 \%$ \\
\hline Total & 414 & \\
\hline
\end{tabular}

\section{Análise do modelo de disposição a pagar}

A Tabela 4 apresenta os resultados dos modelos de regressão Probit da DAP individual para a instituição da taxa adicional de visitação ao PNU. Para fins de análise, foram estimados dois modelos: MP1 - 
modelo probit irrestrito, no qual incluiu-se todas as variáveis explicativas; e MP2 - modelo probit restrito, no qual reteve as variáveis que mostraram significativas ao nível de $10 \%$.

Tabela 4: Modelos probit de disposição a pagar pela preservação do PNU.

\begin{tabular}{|c|c|c|c|c|}
\hline \multirow[t]{2}{*}{ Variável } & \multicolumn{2}{|l|}{ MP1 } & \multicolumn{2}{|l|}{ MP2 } \\
\hline & Coef. & $P>|z|$ & Coef. & $P>|z|$ \\
\hline LANCE & $-0,0432$ & 0,001 & $-0,0453$ & 0,001 \\
\hline SEXO & $-0,0996$ & 0,479 & $E x c^{2}$ & - \\
\hline IDADE & 0,0082 & 0,233 & exc & - \\
\hline ESTCIVIL & 0,4284 & 0,008 & 0,5342 & 0,001 \\
\hline TFAMILIA & $-0,0047$ & 0,918 & exc & - \\
\hline NESCOLAR1 & $-0,0573$ & 0,741 & exc & - \\
\hline NESCOLAR2 & $-0,3208$ & 0,051 & $-0,2868$ & 0,041 \\
\hline NESCOLAR3 & $o m^{1}$ & - & om & - \\
\hline RMF1 & $-0,0345$ & 0,867 & exc & - \\
\hline RMF2 & 0,0591 & 0,778 & exc & - \\
\hline RMF3 & 0,1764 & 0,393 & exc & - \\
\hline RMF4 & $\mathrm{Om}$ & - & exc & - \\
\hline MORGAMB & 0,7846 & 0,007 & 0,8197 & 0,003 \\
\hline OFORTAL & 0,3209 & 0,032 & 0,3943 & 0,006 \\
\hline NVISITAS & $-0,1089$ & 0,099 & $-0,1033$ & 0,108 \\
\hline MULTDEST & 0,4259 & 0,003 & 0,4128 & 0,003 \\
\hline TGRUPO & 0,0145 & 0,407 & exc & - \\
\hline CONST & 0,1171 & 0,773 & 0,4032 & 0,041 \\
\hline \multicolumn{5}{|l|}{ Estatística } \\
\hline Núm. Obs. & \multicolumn{2}{|l|}{406} & \multicolumn{2}{|l|}{413} \\
\hline LR Chi2 (g.l.) & \multicolumn{2}{|l|}{$77,890(16)$} & \multicolumn{2}{|l|}{$78,60(7)$} \\
\hline Prob > Chi2 & \multicolumn{2}{|l|}{0,001} & \multicolumn{2}{|l|}{0,001} \\
\hline
\end{tabular}

Nota: ML1 é o modelo probit irrestrito. ML2 é o modelo probit restrito. (1) om significa variável explicativa omitida do modelo; (2) exc significa variável explicativa excluída do modelo por seu baixo grau de significância no ML1.

O teste de Razão da Verossimilhança mostrou que, em ambos os modelos, as variáveis explicativas são conjuntamente significativas para explicar as escolhas dos visitantes. Desta forma, ambos os modelos são úteis para explicar o comportamento do visitante quanto à sua preferência pela proposta de instituição de uma taxa adicional de preservação do PNU. O MP2, modelo probit restrito, é utilizado para estimar a disposição a pagar média do visitante.

As variáveis explicativas que apresentaram significância ao nível de 5\%, em ambos os modelos, foram o valor do lance (LANCE), estado civil (ESTCIVIL), nível médio de escolaridade (NESCOLAR2), membro de organização ambiental (MORGAMB), origem de Fortaleza (OFORTAL), número de visitas ao PNU (NVISITAS) e viagem de múltiplos destinos (MULTDEST). Embora as demais variáveis não tenham se mostrado significativas, ainda assim são úteis para indicar a direção do efeito marginal de mudanças nessas variáveis sobre a escolha do visitante.

\section{Disposição a pagar média}

A Tabela 5 mostra as frequências, absoluta e relativa, das respostas dos visitantes aos valores propostos para a taxa adicional de ingresso ao PNU. Os lances oferecidos aos visitantes assumiram seis valores: $R \$ 5,00, R \$ 10,00, R \$ 15,00, R \$ 20,00, R \$ 25,00$ e $R \$ 30,00$. Cada lance foi oferecido a um número aproximado de respondentes, entre 67 e 70 visitantes, correspondendo cada grupo a cerca de $17 \%$ da amostra. 
Deve-se destacar que as respostas aos lances se mostraram consistentes com a racionalidade econômica, ou seja, quanto menor o lance maior o percentual de pessoas que aceitaram pagar aquele valor. Desta forma, as escolhas do visitante permitem delinear uma curva de demanda teoricamente consistente com a teoria, ou seja, negativamente inclinada.

Tabela 5: Disposição a Pagar (DAP) por visitante segundo valor do Lance

\begin{tabular}{|c|c|c|c|c|c|c|}
\hline \multirow[t]{2}{*}{ Lance (R\$) } & \multicolumn{4}{|c|}{ Disposição a Pagar } & \multicolumn{2}{|c|}{ Total } \\
\hline & Sim & Percentual & Não & Percentual & $\mathbf{N}$. & Percentual \\
\hline 5 & 51 & $76,1 \%$ & 16 & $23,9 \%$ & 67 & $16 \%$ \\
\hline 10 & 47 & $68,1 \%$ & 22 & $31,9 \%$ & 69 & $17 \%$ \\
\hline 15 & 44 & $62,9 \%$ & 26 & $37,1 \%$ & 70 & $17 \%$ \\
\hline 20 & 32 & $45,7 \%$ & 38 & $54,3 \%$ & 70 & $17 \%$ \\
\hline 25 & 27 & $39,1 \%$ & 42 & $60,9 \%$ & 69 & $17 \%$ \\
\hline 30 & 25 & $36,2 \%$ & 44 & $63,8 \%$ & 69 & $17 \%$ \\
\hline Total & 226 & $54,6 \%$ & 188 & $45,4 \%$ & 414 & $100 \%$ \\
\hline
\end{tabular}

As estimativas da DAP Média pelos métodos não paramétrico e paramétrico e, correspondentes, valores da arrecadação do Parque são apresentados na Tabela 6.

Tabela 6: Estimativas da DAP Média, arrecadação e benefício líquido do PNU

\begin{tabular}{|l|c|c|}
\hline \multicolumn{1}{|c|}{ Método } & DAP Média (R\$) & Benefício Líquido (R\$) \\
\hline Não Paramétrico & 15,27 & $1.570 .000,00$ \\
\hline Paramétrico & 20,63 & $2.062 .683,60$ \\
\hline
\end{tabular}

A DAP Média da amostra, calculada pelo método não paramétrico de Turnbull foi de $\mathrm{R} \$ 15,27$. Com base na DAP média, a arrecadação adicional do PNU é de $\mathrm{R} \$ 6.499,80$ para a amostra de 414 visitantes e de $\mathrm{R} \$ 1.570 .000,00$ para um total de 100.000 visitantes, anualmente. Este valor representa o benefício líquido da visitação ao PNU considerando as melhorias na qualidade ambiental propostas no cenário hipotético sob as condições sugeridas pelo mercado hipotético.

A DAP Média da amostra, calculada pelo método paramétrico, com base no modelo probit restrito (MP2) foi estimada em $\mathrm{R} \$ 20,63$, sendo este maior do que a DAP média não paramétrica. Este valor de taxa

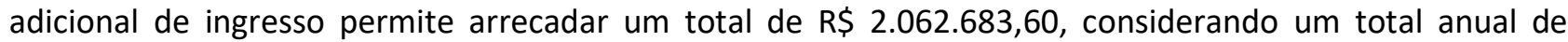
100.000 visitantes.

Comparando as estimativas das médias das DAPs, não paramétrica e paramétrica, observa-se que a segunda se mostrou sobrestimada relativamente à estimativa não paramétrica. Do ponto de vista da eficiência, a taxa adicional mais conservadora deve ser preferida, já que este valor teria um menor impacto sobre o fluxo de visitantes ao PNU e, ainda assim, garantiria uma arrecadação satisfatória para fazer face à gestão do Parque.

Tratando a valoração da instituição de uma taxa adicional de ingresso ao PNU, pareceu indispensável saber sobre a atitude dos visitantes relativa à cobrança desse tributo. Nesse sentido, indagou-se se o respondente estava de acordo ou não com a instituição da taxa. Do total da amostra, 56,8\% afirmaram discordar com esta proposta, ou seja, uma ligeira maioria (Tabela 7).

Os visitantes que apoiaram a proposta manifestando seu sim, o fizeram por reconhecer o valor do PNU para a sociedade (12,8\%), possuir atitudes altruístas e filantrópicas direcionadas às gerações futuras e 
presente $(20,8 \%)$ e esperar que os recursos financeiros permitam melhorar a qualidade do PNU $(12,3 \%)$ e, consequentemente, a experiência de visitação.

Tabela 7: Atitudes do visitante relativo ao pagamento de taxa de ingresso no PNU.

\begin{tabular}{|l|l|l|}
\hline Especificação & Frequência & Relativa \\
\cline { 2 - 3 } & Absoluta & \\
\hline Aceitação da taxa & & $43,2 \%$ \\
\hline Sim & 179 & $56,8 \%$ \\
\hline Não & 235 & \\
\hline Razões para aceitar & & $22,6 \%$ \\
\hline Valor inestimável do Parque & 53 & $36,8 \%$ \\
\hline Altruísmo relativo às gerações presentes e futuras & 86 & $21,8 \%$ \\
\hline Melhoria da experiência de visitação & 51 & $8,1 \%$ \\
\hline Impulsionar a economia local & 19 & $10,7 \%$ \\
\hline Reconhece as dificuldades do Parque & 25 & \\
\hline Razões para não aceitar & & $16,8 \%$ \\
\hline Restrição da renda pessoal & 27 & $16,8 \%$ \\
\hline Desconfia do mal uso do dinheiro & 27 & $24,2 \%$ \\
\hline Obrigação do governo & 39 & $28,0 \%$ \\
\hline Defende a gratuidade dos parques & 45 & $8,7 \%$ \\
\hline Baixa qualidade do Parque & 14 & $5,6 \%$ \\
\hline Discorda da proposta & 9 & \\
\hline
\end{tabular}

Por outro lado, os visitantes que não aceitaram a proposta de instituição de uma taxa adicional de ingresso PNU estavam apoiados na opinião, principalmente, de que o acesso aos parques nacionais deveria ser gratuito (28\%) e ainda que proteção da Natureza é uma obrigação do governo (24,2\%). Igualmente importantes, com $16,8 \%$ das indicações cada, foram a restrição da renda pessoal do visitante e a desconfiança com relação ao mau uso do dinheiro arrecadado. Os visitantes que se opuseram à proposta corresponderam a 5,6\% daqueles que disseram não.

Para os visitantes que aceitaram pagar a taxa adicional, indagou-se sobre seu grau de confiança quanto a importância dessa política para alcançar as metas de preservação da biodiversidade e de melhoria das atividades de recreação, lazer e turismo no PNU. A maioria deles respondeu que estavam confiantes (3), com 113 indicações (ou 50\%), enquanto aqueles muito confiantes totalizavam 48 (ou 21,2\%). Os visitantes com níveis de confiança baixo ou muito baixo corresponderam a $28,8 \%$ das indicações.

\section{DISCUSSÃO}

O maior número de visitantes jovens pode ser explicado pela maior exposição que o público jovem tem tido à educação ambiental, nos dias atuais, e por estarem mais aptos a desenvolverem atividades recreativas que exigem certo esforço físico. Por outro lado, a população jovem predominante no estado do Ceará, já que 54,4\% de pessoas possuem idade de até 30 anos (CEARÁ, 2016).

Em termos médios, a média da renda mensal familiar da amostra foi de $\mathrm{R} \$ 7.032$ ou aproximadamente 8 salários mínimos vigentes em 2016 (R\$ 880,00), apresentando-se muito superior à média da renda mensal familiar observada no Brasil no mesmo ano (R\$1.226) (BRASIL, 2017). Portanto, esses resultados demonstram que o visitante típico do PNU pertence à Classe Social C com renda média mensal entre $\mathrm{R} \$ 3.520,00$ e $\mathrm{R} \$ 8.800,00$, valores acima da média da população cearense que possuía renda domiciliar de R\$ 751,00 (BRASIL, 2017). 
O coeficiente do LANCE apresentou sinal negativo, indicando que quanto maior o valor do lance, menor a disposição a pagar do visitante, sendo tal efeito consistente com a racionalidade econômica. Tanto as variáveis que descrevem o perfil do respondente (ESTCIVIL, NESCOLAR2, MORGAMB) quanto aquelas que descrevem sua viagem (OFORTAL, NVISITAS e MULTDEST) afetaram as escolhas dos visitantes relativas aos lances propostos.

Em relação ao perfil do respondente, observa-se que o coeficiente do ESTCIVIL foi positivo e mostra que o visitante casado ou em regime de união estável está disposto a pagar valor maior da taxa adicional do que os solteiros, separados, divorciados ou viúvos. O sinal do coeficiente do NESCOLAR2, por ser negativo, indica que os visitantes com este nível de escolaridade médio, completo ou incompleto, estão dispostos a pagar valor menor de taxa de ingresso do que os visitantes com outros níveis de escolaridade. O coeficiente da MORGAMB, com sinal positivo, faz entender que visitantes filiados a uma organização de interesse ambiental têm uma disposição a pagar maior do que aqueles não filiados.

Em relação às características da viagem do visitante, depreende-se dos resultados que o visitante cuja origem é a cidade de Fortaleza (OFORTAL) está disposto a pagar valor maior pela taxa adicional de ingresso do que os visitantes de outras localidades. Isto porque a renda média do município de Fortaleza é maior do que a renda média dos outros municípios do Estado.

O coeficiente do NVISITAS, por ser negativo, indica que aqueles que visitam o Parque com maior frequência estão dispostos a pagar uma taxa de ingresso de menor valor. Este resultado está de acordo com a intuição econômica, já que para esse tipo de visitante, a taxa de ingresso do PNU já faz parte do orçamento familiar que precisa ser minimizado.

Os visitantes que planejam fazer viagem de múltiplos destinos (MULTDEST), pelo fato de o coeficiente desta variável ser positiva, tendem a ter uma disposição a pagar maior do que aqueles que viajam com destino único. Isto talvez possa ser explicado pelo fato de que o visitante cuja viagem é de múltiplos destinos possua uma maior capacidade de pagamento, já que pode custear uma viagem de longa duração com múltiplos destinos.

As faixas de renda não se mostraram significantes em explicar a disposição a pagar dos visitantes pela taxa adicional de ingresso. Esse resultado não era esperado, já que a renda é uma restrição importante e condicionam as decisões de consumo das famílias. Isto pode ser explicado pelo fato de a taxa adicional de ingresso não ser um item de gastos frequente no orçamento familiar e seu valor não ser suficiente para levar a um reordenamento de gastos.

Quanto ao fator de participação em organizações de cunho ambiental, o comportamento encontrado nesta pesquisa assemelha-se ao resultado de estudo conduzido pelo Ministério do Meio Ambiente que concluiu que "há grande simpatia pelas organizações que protegem o meio ambiente, mas o conhecimento sobre elas é pequeno e a filiação pouco expressiva" (BRASIL, 2006).

\section{CONCLUSÕES}

Os resultados do presente estudo demonstram que os bens e serviços ambientais ofertados pelo 
Parque Nacional de Ubajara são significativos também em termos monetários, estes sendo, inclusive, superior à de outros espaços especialmente protegidos no Brasil. A iminente perda de qualidade ambiental à qual o parque está sujeito em decorrência de décadas de restrições orçamentárias refletidas na descontinuidade de programas, projetos e ações previstos no plano de manejo pode ser minimizada a partir da mudança de atitude dos tomadores de decisão governamental visto que a sociedade demonstrou disposição a pagar para evitar a perda do bem-estar proporcionado pelo PNU.

Nesse contexto, estima-se que a promoção do parque como um vetor turístico do Ceará em âmbitos regional, nacional e internacional poderá tanto atrair mais visitantes para a região quanto aumentar o tempo de permanência destes, exercendo, assim, impacto positivo na economia local e na sensibilização dos usuários para a preservação do sítio natural.

É determinante, contudo, que somente uma mudança drástica na forma de gestão financeira do parque - como a implantação de taxas de ingresso, por exemplo - poderá ser capaz de dotar a unidade da sustentabilidade financeira necessária à consecução de iniciativas voltadas à conservação dos bens e serviços ambientais existentes, melhorando não somente as experiências de recreação e turismo ecológico, mas, principalmente, a proteção desse patrimônio natural único.

\section{REFERÊNCIAS}

ABEDINI, A.; MOHAMADI, M. H.; SHARAHI, M. K.. Estimating the outdoor recreational value of Lavizan Jungle Park of Tehran using contingent valuation method (CV). Open Journal of Ecology, n.6, p.225-234, 2016. DOI: http://doi.org/10.4236/oje.2016.65023

BARAL, N.. Estimating the value of the World Heritage Site designation: a case study from Sagarmatha (Mount Everest) National Park, Nepal. Journal of Sustainable Tourism, p.116, 2017. DOI:

http://doi.org/10.1080/09669582.2017.1310866

BRAGA, P. L. S.; ABADALLAH, P. R.; OLIVEIRA, C. R.. Valoração econômica do Parque Nacional da Lagoa do Peixe, RS. In: CONGRESSO DA SOCIEDADE BRASILEIRA DE ECONOMIA, ADMINISTRAÇÃO E SOCIOLOGIA RURAL, 51. Anais. Belém: SOBER, 2013.

BRASIL. Decreto n.72.144: Altera o artigo $2^{\circ}$ do Decreto $n^{\circ}$ 45.954, de 30 de abril de 1959, que cria o Parque Nacional de Ubajara, Estado do Ceará. Brasília: DOU, 1973.

BRASIL. Decreto S/N: Amplia os limites do Parque Nacional de Ubajara, no município de Ubajara, no Estado do Ceará. Brasília: DOU, 2002.

BRASIL. IBGE divulga o rendimento domiciliar per capita. Brasília: IBGE, 2017.

BRASIL. Lei n.9.985: Regulamenta o art. 225, § 10, incisos I, II, III e VII da Constituição Federal, institui o Sistema Nacional de Unidades de Conservação da Natureza e dá outras providências. Brasília: DOU, 2000.
CARVALHO, D. R.. O Parque Nacional da Chapada da Diamantina: o valor econômico da paisagem centrada no sujeito e no espaço. Revista GeoNordeste, São Cristóvão, n.2, p.155-178, 2012.

CEARÁ. Ceará em Números 2016. Fortaleza: IPECE, 2016.

GONZÁLEZ, M. V.. Benefício econômico do Parque Nacional de Cerro Corá. Tese (Doutorado) - Universidade de São Paulo, São Paulo, 2009.

IBAMA. Instituto Brasileiro do Meio Ambiente e dos Recursos Naturais Renováveis. Portaria n.170: Estabelece o plano de manejo do Parque Nacional de Ubajara/CE. Brasília: DOU, 2002

HENEMANN, W. M.; KANNINEN, B.. The statistical analysis of discrete response CV data. Thesis (PhD in Agricultural and Resource Economics) - University of California at Berkeley, 1996.

LÓPEZ-FELDMAN, A.. Introduction to Contingent Valuation Using Stata. MAPA, 2012.

MINGOTI, S. A.. Análise de dados através de métodos de estatística multivariada: uma abordagem aplicada. Belo Horizonte: UFMG, 2005

MITCHELL, R. C.; CARSON, R. T.. Using Surveys to Value Public Goods: the contingent valuation method. Washington: Resources for the Future, 1989.

OECD. Cost-Benefit Analysis and the Environment: further developments and policy use. Paris: OECD Publishing, 2018. 
RESENDE, F.; FERNANDES, G. W. A.; ANDRADE, D. C.; NEDE, H. D.. Valoração econômica do Parque Nacional da Serra do Cipó (Minas Gerais): uma aplicação do método contingente. In: ANPEC - ASSOCIAÇÃO NACIONAL DOS CENTROS DE
PÓSGRADUAÇÃO EM ECONOMIA. Anais. 2014.

MOTTA, R. S.. Manual para Valoração Econômica de Recursos Ambientais. Rio de Janeiro: CEMA/IPEA, 1997.

A CBPC - Companhia Brasileira de Produção Científica (CNPJ: 11.221.422/0001-03) detém os direitos materiais desta publicação. Os direitos referem-se à publicação do trabalho em qualquer parte do mundo, incluindo os direitos às renovações, expansões e disseminações da contribuição, bem como outros direitos subsidiários. Todos os trabalhos publicados eletronicamente poderão posteriormente ser publicados em coletâneas impressas sob coordenação da Sustenere Publishing, da Companhia Brasileira de Produção Científica e seus parceiros autorizados. Os (as) autores (as) preservam os direitos autorais, mas não têm permissão para a publicação da contribuição em outro meio, impresso ou digital, em português ou em tradução. 